Research Paper

\title{
Notch as a Possible Cell Differentiation Factor in Pleomorphic Adenomas
}

\author{
Keisuke Takamine ${ }^{1}$, Yukiko Ueda ${ }^{1}$, Keisuke Nakano ${ }^{1,2}$, Takanaga Ochiai ${ }^{1}$, Yoshihiko Sugita ${ }^{3}$, Katsutoshi \\ $\mathrm{Kubo}^{3}$, Hatsuhiko Maeda ${ }^{3}$, Hiromasa Hasegawa ${ }^{1}$ and Toshiyuki Kawakami ${ }^{\circledR}$ \\ 1. Hard Tissue Pathology Unit, Matsumoto Dental University Graduate School of Oral Medicine, Shiojiri, Japan \\ 2. Department of Oral Pathology, Okayama University Graduate School of Medicine, Dentistry and Pharmacuitical Sciences, Okayama, Japan \\ 3. Department of Oral Pathology, School of Dentistry, Aichi Gakuin University, Nagoya, Japan \\ $\triangle$ Corresponding author: kawakami@po.mdu.ac.jp
}

(C) 2015 Ivyspring International Publisher. Reproduction is permitted for personal, noncommercial use, provided that the article is in whole, unmodified, and properly cited. See http://ivyspring.com/terms for terms and conditions.

Received: 2015.06.05; Accepted: 2015.08.09; Published: 2015.09.05

\begin{abstract}
The expression of Notch in 30 cases of pleomorphic adenoma was examined by immunohistochemistry. Comparing the results of our study with previous literatures, from the partial CK7 expression and substantial Notch expression in ductal epithelial cells as well as the Notch expression in solid tumor nests, it can be inferred that Notch is involved in cell differentiation. CK13 expression was observed in cells undergoing squamous metaplasia and Notch expression was seen in the nucleus of basal and squamous cells. The intense Notch expression in basal cells and weak expression in squamous cells suggests that Notch is involved in the differentiation from basal to squamous cell. Moreover, the loss of nuclear expression on the inner layer would signify that differentiation is about to end or has been terminated. Notch was expressed in the cytoplasm of cartilage cells and in the cell membrane of mucous cells but not in the nucleus indicating that differentiation has been concluded. Notch involvement is suspected in cell differentiation in areas showing ductal structures and squamous metaplasia. In summary, Notch is involved in cell differentiation of ductal cells in PA. Nuclear expression was shown in tumor cells in solid nests and surrounding structures. Moreover, Notch is expressed by basal cells undergoing squamous metaplasia suggesting the participation of Notch in cell differentiation in PA.
\end{abstract}

Key words: Notch1, pleomorphic adenoma, cell differentiation, immunohistochemistry

\section{Introduction}

Pleomorphic adenoma (PA) is the most common salivary gland tumor classified as benign epithelial tumors (1). Various cell types can be seen in the tumor indicating a high occurrence of cell differentiation. Okuda et al. performed immunohistochemistry on PA to determine the role of Wnt in cell differentiation (2). The results suggested that Wnt is involved in cell differentiation in PA. In the present study, we considered that Notch might also be involved in cell proliferation and differentiation in the same manner that Okuda et al. did on Wnt (3).

In this study, we focused on Notch expression in PA since it has been hypothesized to be strongly associated with neoplastic cell differentiation. Moreover, studies on the expression of Notch have been tremendously increasing.

\section{Materials and Methods}

Tissue samples from Department of Oral Pathology, School of Dentistry, Aichi Gakuin University, diagnosed histologically as PA were further re-evaluated for the purpose of this research. A total of 30 cases of PA based on WHO classification were used in this experiment. The specimens used in this study were the same as those used by Okuda et al. (2), described in Table 1.

Specimens were fixed in neutral buffered formalin solution, subjected into series of alcohol for dehydration and then embedded in paraffin. Then after, the specimens were serially sectioned into $4 \mu \mathrm{m}$ 
stained with hematoxylin and eosin and examined under a light microscope.

Table 1. Cases examined

\begin{tabular}{|c|c|c|c|c|}
\hline Age & & Sex & Location & \\
\hline \multirow[t]{6}{*}{ Average } & 51.5 & Male & Palate & 14 \\
\hline & & Female 17 & Parotid gland & 5 \\
\hline & & & Mandibular gland & 4 \\
\hline & & & Upper lip & 3 \\
\hline & & & Buccal mucosa & 3 \\
\hline & & & Other & 1 \\
\hline
\end{tabular}

Immunohistochemistry was performed in the following manner. Briefly, deparaffinized sections were pre-treated for antigen retrieval in citrate buffer (Mitsubishi Chemical Medience, Tokyo, Japan) with a $\mathrm{pH}$ of 6.0 and placed in autoclave at $120^{\circ} \mathrm{C}$ for $15 \mathrm{~min}$. Then after, sections were covered with serum-free protein block (Dako Japan Co., Ltd., Tokyo, Japan), incubated at room temperature for $30 \mathrm{~min}$. Notch1 rabbit polyclonal antibody (Anti-Notch-1 intracellular domain antibody, ab83232, Abcam, Cambridge, UK) was used as the primary antibody. This was followed by staining with Dako Chem Mate Envision Kit (Dako). Antigenic sites were revealed using DAB.

Immunofluorescent staining was also performed using Notch1 rabbit polyclonal antibody, CK7 mouse monoclonal antibody (1:100; Abcam) and CK13 mouse monoclonal antibody (AE8; 1:100; Abcam). Double staining was done by combining Notch1 and CK7 as well as Notch1 and CK13. After deparaffinization, Notch1-CK7 and Notch1-CK13 were pre-treated in citric acid buffer (Mitsubishi Chemical Medience, Tokyo, Japan) with a $\mathrm{pH}$ of 6.0 and placed in microwave for $1 \mathrm{~min}$. Then after, sections were covered with serum-free protein block (Dako), incubated at room temperature for $30 \mathrm{~min}$. The primary antibodies Notch1 and CK7 (1:100; Can Get Signal, Toyobo Co.,, Osaka, Japan) were allowed to react at 4 ${ }^{\circ} \mathrm{C}$ for 16 hours. For the secondary antibody, Donkey anti-rabbit IgG H\&L (1:200; Alexa Fluor 594; Abcam) and Donkey anti-mouse IgG H\&L (1:200; Alexa Fluor 488; Abcam) were carried out after reaction with Can Get Signal (Toyobo) at 1:200 at room temperature for $60 \mathrm{~min}$. DAPI was allowed to react for $3 \mathrm{~min}$ for nuclear staining. The present study was approved by the ethics committee of Aichi Gakuin University, School of Dentistry under the title "Diagnosis and Clinicopathological Study on the Elucidation of Salivary Gland Tumors' (No. 284, December 5, 2011).

\section{Results}

\section{Histopathological examination}

Generally, the tumor consists of various tissue types with small and/or large duct-like/cystic spaces in the tissues. The tumor is round in shape and covered with relatively thin fibrous connective tissue. The substantial portion of the tumor consists of glandular structures of tumor nests surrounded by fibrous tissue. The tumor is clearly separated from the normal salivary gland tissues. The tumor stroma consists of duct-like structures predominantly ductal and myoepithelial cells forming cystic cavities.

The mesenchymal part consists of myoepithelial cells, spindle shaped cells and myxoma-like tissue formed by round or oval cells dissociated from the tumor growth. In some areas, cartilage-like tissues can be characteristically observed (Fig. 1-a). In myxomatous areas, the myoepithelial cells have sparsely formed cord-like structures and the presence of mucous was confirmed. Cartilage-like tissues can be seen in a wide range possibly due to the presence of cartilage-like matrix and cartilage-like cells. Neoplastic myoepithelial cells are dissociated from the mucous or cartilage-like substrate by their own secretions. The tumor parenchyma might have been formed by myxomatous cells, which migrated to seep into the structure of mesenchymal and cartilage-like cells. Thus, the epithelial component is dissociated and mixed into the mesenchymal-like tissue, giving rise to a 'mixed appearance'. Moreover, tumor cells undergo remarkable squamous metaplasia (Fig. 1-b).

\section{Immunohistochemical findings}

Notch1 expression was observed in the cytoplasm of ductal epithelial cells as well as in some of the nuclei. Notch expression was also observed in the nucleus of tumor cells surrounding solid tumor nests (Fig. 1-c).

Notch was expressed in the cytoplasm of plasmacytoid myoepithelial cells but not in the nucleus. In areas undergoing squamous metaplasia, Notch was strongly expressed in the cytoplasm and nucleus of basal cells. However, the expression became weak towards the outer squamous cells (Fig. 1-d).

The cartilage-like cells representing the characteristic feature of PA showed strong cytoplasmic expression but not nuclear reaction (Fig. 1-e). Likewise, the myoepithelial cells in myxomatous area showed faint expression on the cell membrane but no cytoplasmic or nuclear reaction were detected (Fig. 1-f).

Ductal epithelial cells expressed CK7 (Fig. 2-a). Notch was also detected in the nucleus of some ductal epithelial cells (Fig. 2-b). Double immunofluorescent staining revealed that Notch and CK7 were co-expressed by tumor cells in ductal structures. Notch expression was observed in most of the nucleus of tumor cells in solid nests as well as those in ductal structures (Fig. 2-c, d). 
The expression of CK13 in tumor cells undergoing squamous metaplasia was also observed. CK13 showed positive reaction on basal and prickle cell layers (Fig. 3-a). On the other hand, Notch was observed in the nucleus from basal cell to squamous cells (Fig. 3-b). Double immunofluorescent staining of

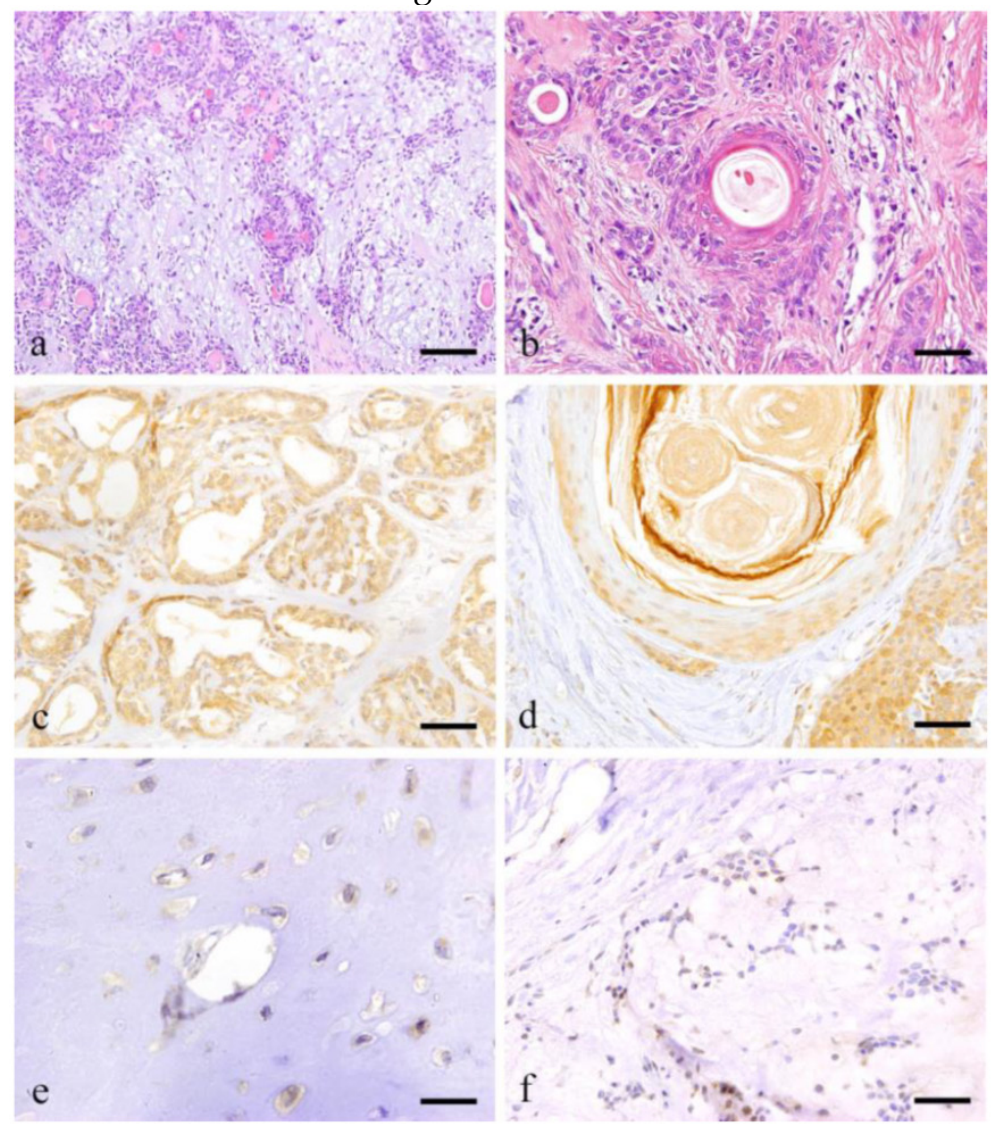

Figure 1. Histopathologcal features of typical PA (a: Case 9: 28 year-old female, the right palatal region; scale bar=200 $\mu$ ), squamous metaplasia with keratin pearl (b: Case 30:


bar $=100 \mu \mathrm{m}$ ), in squamous metaplasia area (d: Case 18: 69 year-old female, right buccal mucosa; scale bar=100 $\mu \mathrm{m})$, immunohistochemical features of cartilage-like area (e: Case 18: 69 year-old female, right buccal mucosa; scale bar $=20 \mu \mathrm{m}$ ) and myxomatous area (f: Case 18: 69 year-old female, right buccal mucosa; scale bar=50 $\mu \mathrm{m}$ ).
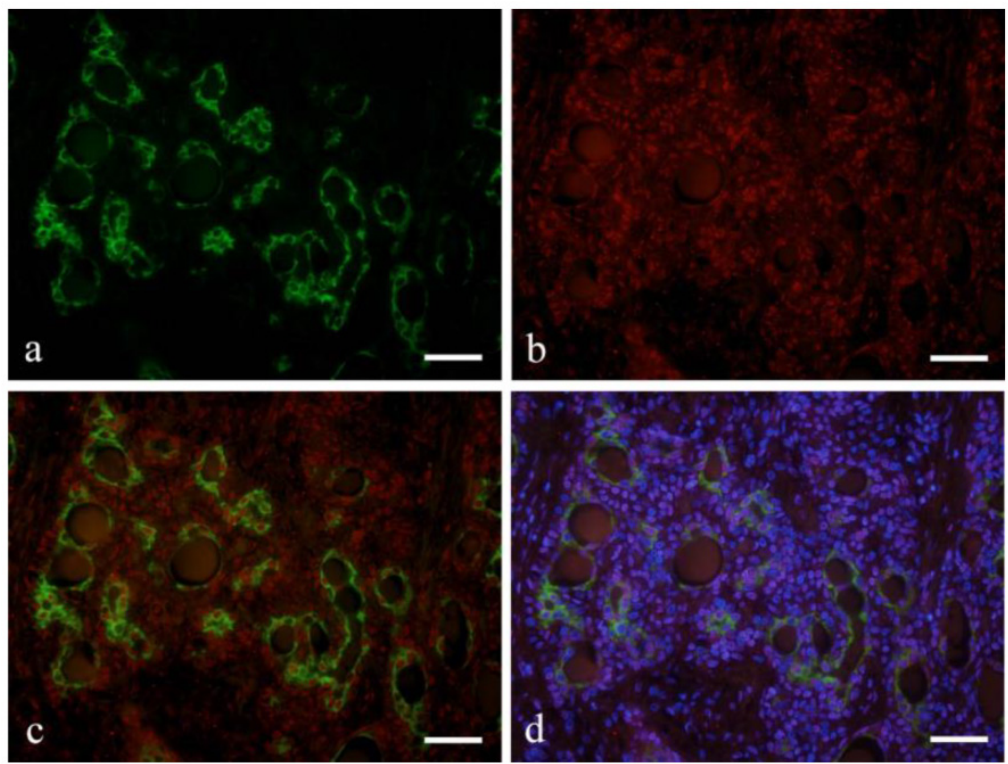

Figure 2. Immunofluorescent staining images of ductal structure forming area (a: CK7; b: Notch 1; c: merged image of CK7 and Notch1; and d: merged image of CK7 and Notch1 and DAPI; Case 28: 39year-old male, submandibular region; scale bar=100 $\mu \mathrm{m}$ ). 

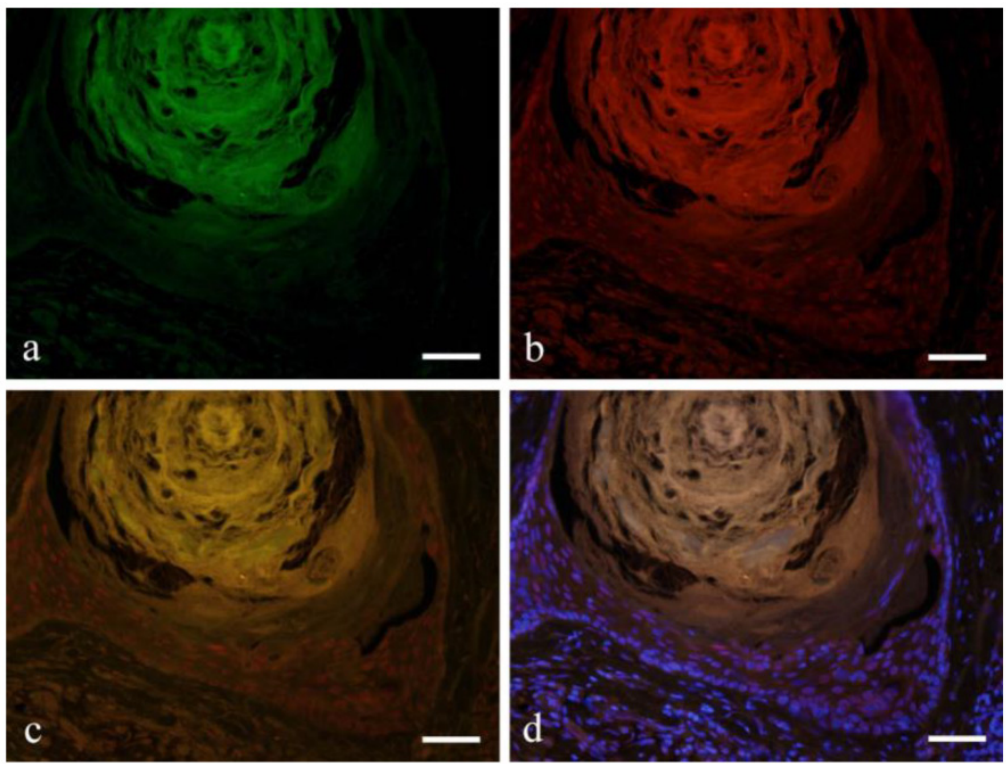

Figure 3. Immunofluorescent staining images of squamous metaplasia area with keratin pearl (a: CK13; b: Notch1; c: merged image of CK13 and Notch1; and d: marged image of CK13 and Notch1 and DAPI; Case 18: 69 year-old female, right buccal mucosa; scale bar=100 $\mu \mathrm{m})$.

\section{Discussion}

PA is the most common benign epithelial tumor of salivary glands based on WHO classification (1). The tumor shows a wide variety of tumor development brought about by cell proliferation and differentiation as mentioned in previous studies (4-6).

Okuda et al. studied the expression of Wnt in 30 cases of PA. The results showed that tumor cells in ductal structure and in solid tumor nests expressed Wnt. It was inferred that $\beta$-catenin pathway was involved in cell differentiation indicated by Wnt expressions in cells undergoing squamous metaplasia (2). For this reason, we believed that Notch would have a role in tumor cell differentiation considering its association with other tumors $(7,8)$.

Notch appears as a typical signal that controls the growth of tissues responsible for the fate of cells (9). Notch is a single-pass transmembrane receptor with a domain outside and inside the cell membrane. Notch intracellular domain (NICD) is cleaved and binds to a ligand such as Jagged. Cleaved NICD is moved from the cell membrane into the cytoplasm, binds with Suppressor of Hair-less $(\mathrm{Su}(\mathrm{H}))$ to form a complex and acts on downstream target gene in the nucleus thus activating the expression (10). In addition to the role of transmitting instructions for various morphogenesis and tissue differentiation during development, Notch plays an important role in cell-cell signaling and is involved in stem cell maintenance, differentiation and neuronal function in adult.

When there is a disturbance in the activity of Notch signaling pathway, it becomes oncogenic detected in several cancers such as esophageal cancer, breast cancer and lymphoblastic acute leukemia (T-ALL) $(11,12)$. In addition, Notch has been the focus of researches on the metastasis of malignant tumors such as adenoid cystic carcinoma and malignant ameloblastoma $(13,14)$, believed to be a huge factor in the progress of malignant tumors.

Studies in Notch have been done in odontogenic tumors such as ameloblastoma (15-17). Notch is expressed in solid nests and in squamous metaplasia in ameloblastoma, implicating its contribution in cell differentiation and morphogenesis. Moreover, in calcifying cystic odontogenic tumor, calcifying epitheioma (pilomatrixoma), odontoma and craniopharyngioma, Notch expression in ghost or shadow cells was observed (18-20). Notch overexpression in ghost cells inhibited the development of neighboring cells. This means that Notch inhibits the production of a ligand in receiving cell signal between Notch ligand and Notch receptor to adjacent cells through a negative feedback mechanism. In contrast, during binary cell fate determination, Numb acts an inhibitor of Notch signaling cycle causing asymmetric distribution of the Notch pathway. This led to overexpression suggesting that Notch-Jagged1 is the primary mechanism in determining the fate of ghost cell (21).

Squamous metaplasia depicted as having a variety of cell differentiation is commonly observed in odontogenic tumors such as ameloblastoma. Squamous metaplasia can also be observed in PA. Muraki et al suggested a close relationship between Notch and ameloblastoma shown by the localization of Notch in peripheral tumor nests (15). From this aspect, we suspected that Notch might also be involved in cell differentiation in PA. 
Comparing the results of our study with previous reports, from the partial CK7 expression and substantial Notch expression in ductal epithelial cells as well as the Notch expression in solid tumor nests, it can be inferred that Notch is involved in cell differentiation $(2,22)$. CK13 expression was observed in cells undergoing squamous metaplasia and Notch expression was seen in the nucleus of basal and squamous cells (23). The intense Notch expression in basal cells and weak expression in squamous cells suggests that Notch is involved in the differentiation from basal to squamous cell. Moreover, the loss of nuclear expression on the surface layer would signify that differentiation is about to end or has been terminated. Notch was expressed in the cytoplasm of cartilage cells and in the cell membrane of mucous cells but not in the nucleus indicating that differentiation has been concluded.

Notch involvement is suspected in cell differentiation in areas showing ductal structures and squamous metaplasia. In the study by Okuda et al, small cuboidal cells forming ductal structure expressed Wnt and the expression was also confirmed in the basal cells surrounding those cells undergoing squamous metaplasia. The results coincided with our present study implicating the function of Notch in the same sites causing cell differentiation (2).

In summary, Notch is involved in cell differentiation of ductal cells in PA. Nuclear expression was shown in tumor cells in solid nests and surrounding structures. Moreover, Notch is expressed by basal cells undergoing squamous metaplasia suggesting the participation of Notch in cell differentiation in PA.

\section{Acknowledgments}

This study was supported in part by a Grant-in-Aid for Scientific Research (C) (\# 23592951 and \#26463031) from the Japan Society for the Promotion of Science.

\section{Competing Interests}

The authors have declared that no competing interest exists.

\section{References}

1. Eveson JW, Kusafuka K, Stenman G and Nagano T. Pleomorphic adenoma. In: Barnes L, Eveson JW, Reichart P and Sidransky D, eds. World Health Organization Classification of Tumours. Pathology and Genetics of the Head and Neck Tumours. Lyon, France: IARC Press. 2005: 254-60.

2. Okuda Y, Nakano K, Suzuki K, Sugita Y, Kubo K, Maeda H, Okafuji N, Hasegawa $\mathrm{H}$ and Kawakami $\mathrm{T}$. Wnt signaling as a possible promoting factor of cell differentiation in pleomorphic adenomas. Int J Med Sci 2014; 11: 971-8.

3. Siar $\mathrm{CH}$, Nakano $\mathrm{K}, \mathrm{Ng} \mathrm{KH}$, Tomida $\mathrm{M}$, Nagatsuka $\mathrm{H}$ and Kawakami $\mathrm{T}$. Squamous odontogenic tumor of the mandible: a case report demonstrating immunoexpression of Notch1, 3, 4, Jagged1 and Delta1. Eur J Med Res 2010; 15: $180-4$

4. Ohtomo R, Mori T, Shibata S, Tsuta K, Maeshima AM, Akazawa C, Watabe Y, Honda K, Yamada T, Yoshimoto S, Asai M and Okano H. Sox10 is a novel marker of acinus and intercalated duct differentiation in salivary gland tu- mors: a clue to the histogenesis for tumor diagnosis. Mod Pathol 2013; 26: 1041-50.

5. Boecker W, Stenman G, Loening T, Andersson MK, Bankfalvi A, von Holstein S, Heegaard S, Lange A, Berg T, Samoilova V, Tiemann K and Buchwalow I. K5/K14-positive cells contribute to salivary gland-like breast tumors with myoepithelial differentiation. Mod Pathol 2013; 26: 1086-100.

6. Tsuneki M, Maruyama S, Yamazaki M, Essa A, Abe T, Babkair HA, Ahsan MS, Cheng J and Saku T. Podoplanin is a novel myoepithelial cell marker in pleomorphic adenoma and other salivary gland tumors with my oepithelial differentiation. Virch Arch 2013; 462: 297-305.

7. Sun W, Gaykalova DA, Ochs MF, Mambo E, Arnaoutakis D, Liu Y, Loyo M, Agrawal N, Howard J, Li R, Ahn S, Fertig E, Sidransky D, Houghton J, Buddavarapu K, Sanford T, Choudhary A, Darden W, Adai A, Latham G, Bishop J, Sharma R, Westra WH, Hennessey P, Chung CH and Califano JA. Activation of the Notch pathway in head and neck cancer. Cancer Res 2014; 74: 1091-104.

8. Yap L, Lee D, Khairuddin A, Pairan M, Puspita B, Siar C and Paterson I. The opposing roles of Notch signaling in head 8and neck cancer: A mini review. Oral Dis 2015; doi: 10.1111/odi. 12309

9. Lobry C, Oh P, Mansour MR, Look AT and Aifantis I. Notch signaling: Switching an oncogene to a tumor suppressor. Blood 2014; 123: 2451-9.

10. Yamamoto S, Schulze KL and Bellen HJ. Introduction to Notch signaling. Methods Mol Biol 2014; 1187: 1-14.

11. Doi K, Imai T, Kressler C, Yagita H, Agata Y, Vooils M, Hamazaki Y, Inoue J and Minato N. Crucial role of the Rap G protein signal in Notch activation and leukemogenicity of T-cell acute lymphoblasticleukemia. Sci Rep 2015; 5: 7978.

12. Wang T, Xuan X, Pian L, Gao P, Hu H, Zheng Y, Zang W and Zhao G. Notch-1-mediated esophageal carcinoma EC-9706 cell invasion and metastasis by inducing epithelial-mesenchymal transition through Snail. Tumour Biol 2014; 35: 1193-201.

13. Ding LC, She L, Zheng DL, Huang OL, Wang JF, Zheng FF and Lu YG. Notch-4 contributes to the metastasis of salivary adenoid cystic carcinoma. Oncol Rep 2010; 24: 363-8.

14. Nakano K, Siar $\mathrm{CH}$, Tsujigiwa $\mathrm{H}$, Nagatsuka $\mathrm{H}$, Nagai $\mathrm{N}$ and Kawakami T. Notch signaling in benign and malignant ameloblastic neoplasms. Eur J Med Res 2008; 13: 476-80

15. Muraki E, Nakano K, Maeda H, Takayama M, Jinno M, Kubo K, Yoshida W, Hasegawa $\mathrm{H}$ and Kawakami T. Immunohistochemical localization of Notch signaling molecules in ameloblastomas. Eur J Med Res 2011; 16: 253-7.

16. Siar CH, Nagatsuka H, Chuah KS, Rivera RS, Nakano K, Ng KH and Kawakami T. Notch4 overexpression in ameloblastoma correlates with the solid/multicystic phenotype. Oral Surg Oral Med Oral Pathol Oral Radiol Endod 2010; 110: 224-33.

17. Siar $\mathrm{CH}, \mathrm{Nakano} \mathrm{K}$, Han PP, Nagatsuka H, Ng KH and Kawakami T. Differential expression of Notch receptors and their ligands in desmoplastic ameloblastoma. J Oral Pathol Med 2010; 39: 552-8.

18. Mehendiratta M, Bishen KA, Boaz K and Mathias Y. Ghost cells: A journey in the dark.... Dent Res J (Isfahan) 2012; 9 (S1): S1-8.

19. Rumayor A, Carlos R, Molina Kirsch H, de Andrade BA, Romanach MJ and de Almeida OP. Ghost cells in pilomatrixoma, craniopharyngioma, and calcifying cystic odontogenic tumor: Histological, immunohistochemical, and ultrastructural study. J Oral Pathol Med 2015; 44: 284-90.

20. Gomes da Silva W, Ribeiro Bartholomeu dos Santos TC, Cabral MG, Azevedo RS and Pires FR. Clinicopathologic analysis and syndecan-1 and Ki-67 expression in calcifying cystic odontogenic tumors, dentinogenic ghost cell tumor, and ghost cell odontogenic carcinoma. Oral Surg Oral Med Oral Pathol Oral Radiol 2014; 117: 626-33.

21. Lee SK and Kim YS. Current concepts and occurrence of epithelial odontogenic tumors: II. Calcifying epithelial odontogenic tumor versus ghost cell odontogenic tumors derived from odontogenic cyst. Korean J Pathol 2014; 48: 175-87.

22. Ihrler S, Schwarz S, Zengel P, Guntinas-Lichius O, Kirchner T and Weiler C. Pleomorphic adenoma: Pitfalls and clinicopathological forms of progression. Pathologe 2009; 30: 446-56.

23. Yamamoto $\mathrm{O}$ and Yasuda $\mathrm{H}$. An immunohistochemical study of the apocrine type of cutaneous mixed tumors with special reference to their follicular and sebaceous differentiation. J Cutan Pathol 1999; 26: 232-41. 